\title{
The Problem Awareness, Critical Spirit and Activism Style of Social Theme Documentary in Taiwan
}

\author{
$\mathrm{Hu}$ Zhou \\ Huaiyin Normal University \\ Huaiyin, China
}

\begin{abstract}
The video recording activities that insisted on realism returned to the stage of documentary after the martial law was abolished in Taiwan in 1980s. The social theme documentary reopened the window for the Taiwanese to understand social reality. These works present strong problem awareness and humane care, involving in the social public issues to a large extent, moreover, with the intense critical spirit and activism style demonstrated in the video. The appearance and spreading of such social theme documentary play an important role in holding together the publicity of social space.
\end{abstract}

Keywords-Taiwan; documentary; problem awareness; critical spirit; activism

\section{INTRODUCTION}

Along with the loosening of authoritarian political system in Taiwan in the mid-late 1980s, the folk force emerged in every corner of the society subtly. Moreover, the video recording activities that insisted on realism returned to the stage of documentary, and the social theme documentary reopened the window for the Taiwanese to understand social reality. Social theme documentary refers to "the documentary with objects that currently present or those are already existed but have just been found, involving ordinary people's life and emotion, revealing people's life and convening the views and appeal of a certain group or different groups."[1] The development of Taiwan social theme documentary has undergone the phases of equipment renewal, issue breakthrough and formal development over the past three decades. In addition, the cultivation of documentary talents was strengthened, documentary union was established, a variety of film festivals were held and a large number of quality works sprang up. These works present strong problem awareness and humane care, involving in social public issues to a large extent. In addition, the intense critical spirit and activism style are demonstrated in the video. The appearance and spreading of such social theme documentary play an important role in holding together the publicity of social space.

\section{PROBLEM AWARENESS IN TAIWAN SOCIAL THEME DOCUMENTARY}

After making a general survey of the documentaries in Taiwan, we find that some of them belong to the type of selfviewing that shoot self experience, having no relationship to social public life experience, filling with photographer's lengthy narration, and are called by the documentary scholar
Guo Lixin as "navel vision". Although individual experience has its own value, the narrow viewing and expression of such view are not sufficient to be expanded as extensive public experience, nor can it arouse sufficient reaction and profound cognition. Some other documentaries are expressed as sentimentalism, presenting the superficial phenomenon of things using over-emotional and highly rhetorical image language, neglecting the logic and problem behind the things. All the above categories cannot present the value and aesthetic standard of documentary due to weak problem awareness or lack of problem awareness.

As the starting point of documentary creative thinking, problem awareness contains the aspects such as why shoot a documentary, what does the creation need to express, what kind of problem is to be presented, and what kind of effect is expected to generate on the audiences. Documentary is considered as the mirror of human survival, which restores history and truth based on real image. Documentary itself bears the issues such as recording the condition of human existence, social development and change, requiring the creator to go down to grassroots to experience, observe and excavate, and this is the source of problem awareness of documentary. Realizing existence of problems is the starting point of thinking, while the thinking without problem is superficial and passive thinking. Guo Lixin, a scholar in Taiwan, once gave such opinion "how to politicize and problematize the film materials to a certain extent in any public issue and even individual experience. How to make the audiences grasp the context of imaging materials to get the more sophisticated and structural understanding, rather than to simplify our recognition of reality or to make our recognition of the world stay at the existing state prior to watching this documentary film beyond the surface of the person, event, or phenomenon recorded in the film." [2]

In Taiwan social documentaries, the most outstanding issues reflected by the problem awareness are issues involve in social public, and the ones showing social affairs, cultural phenomenon and public life experience. Facing the conditions in the course of social development such as environmental pollution, urban change and community integration, those persistent documentary creators have a keen eye on the existence of problems, getting deep to shoot the issues of social development and changes, analyzing and discussing the social problems and institutional barriers which are avoided in the past, and trying hard to explore the profound motivation and the essence of the problem behind the phenomenon. The 
creators of such kind of documentaries pay more attention to social public affairs and issues compared with the problem orientation of bottom layer such as people's livelihood and people orientation in the new recording movement emerged in the mainland in 1990s. Such documentaries express civic awareness and public consciousness based on record video language, aiming to arouse the audiences' cognition and awakening and strive to improve the public's willingness and motivation to participate in the public life.

The creator of realistic image is required to have the ability of grasping actual phenomenon and excellent image narrative ability on the basis of problem awareness, so as to display the persuasion and infection. Cai Chonglong, the former documentary producer of Taiwan public television, created The Other Side and Surviving Evil with an eye to the justice, multi-culture, environmental protection and other problems in Taiwan, and has attracted broad attention at home and abroad. In 2006, Taipei Documentary Practitioners Professional Union, the first independent union initiated by documentary workers, was established, with the members including young, middleaged and old professionals of documentary director, photographer, editor, soundtrack and curator. Their purpose is to safeguard the basic labor rights of documentary workers, enhance the professional level of documentary work and promote documentary industry development. Zhuang Yizeng, Yan Lanquan, Chen Liangfeng, Zeng Wenzhen and Li Huiren of the Union have grown into excellent documentary creators. The significance of Secret that cannot be Revealed, Reconstruction by Daniuzhuang Villagers, Let It Be and other documentaries is not the wide repercussions won through screening on Taiwan public television and the encouragement gained from various film festival awards, what is more is its provision of thinking windows and channels for the public, which has promoted the mature development of Taiwan civil society and the public domain.

\section{CRITICAL SPIRIT OF TAIWAN SOCIAL THEME DOCUMENTARY}

Critical spirit is an important mark of human civilization progress. Criticism refers to inspect history and reality as well as to analyze person or event from a higher perspective, so as to discover and solve the problems. Critical spirit of documentary refers to that the creator finds problems with documentary images, displays powerful evidences and puts forward sharp questions under the premise of strong problem awareness on the basis of extensive research. The important guarantee for making documentary includes exploring issues, setting reality, seeking the truth and deconstructing narration. In addition, it is required to continue to establish and exercise the spiritual personality of images, so as to response the common problems in community, society and even various large spaces, providing more profound "visual sample" for the audiences to recognize and make clear the root of problem and the complex relationship behind the problem.

Zhang Hongjun, a scholar, once put forward that "the problem of documentary's lack of sense of heaviness points out a basic problem existing in the creation of most documentaries, namely avoiding reality frontier. Paying too much attention to "nobody" and marginal man lead to missing of large subject and flooding of public tender feeling, as well as generalization of video recording style."[3] When all the creators dare not to touch the root of social issues, and just create the so-called fresh and sensational visual material to satisfy audiences' consumption, the society may stagnate due to the lack of "different voices".

The significance of documentary lies in the collision between director and history as well as reality and people to a large extent. In this process, the position and awareness of the director himself directly determines the narrative style and quality of the documentary. [4] Most creators create Taiwan society theme documentary independently, and they have more difficulties than creators within the system in terms of creative resources, funding conditions and showing space. Although the documentary with themes of freshness, sentimentality, warmth and inspiration can help to get funding from government and enterprises or obtain the box office revenues from commercial theaters, such kind of creation may violate the true and objective documentary ethics and run counter to the spirit advocated by the documentary, let alone the critical and reflective expression. Creators who have real courage to get involved in society and to face the reality and criticism are decreasing. However, Taiwan documentary workers represented by Li Huiren ignite the flame of critical spirit in images, just as what Lin Mucai said "their documentaries always contain something that the capital giants unable to swallow or that may be spat out even they swallowed. This is a kind of ability to ponder over existing system, and a kind of rebellious spirit which is difficult to control.'[5]

The documentary Secret that cannot be Revealed, once won the survey report award of TV category of Taiwan Tenth Award for Excellent Journalism (2011), describes the avian influenza evolution and spread due to the government's hiding and even alteration of experimental data in Taiwan from the year 2006 to 2011. This film discusses the problems of government departments' lack of sense of responsibility and "mutually making excuses" among the departments in the course of avian influenza prevention. Director Li Huiren creates documentaries with a scientific attitude. He uncovered the lie of Agriculture Commission to conceal the situation of avian influenza and completed the documentary through independent investigations such as field research, expert visits, data collection, the use of hidden interview recording and other methods, with logical discussion as the core. After this documentary was screened publicly on the network platform, it created a public stir and led the public to pay attention to avian influenza and to blame the public authority. This social documentary is a typical case in which the creator faces social problem directly with critical expression and discusses the neglected public issues. Li Huiren presents the whole problem from multiple dimensions based on scientific attitude, and puts forward questions and criticisms bravely against public authorities, having aroused social attention and thinking. For the documentary creator, the courage to challenge and criticize is extremely valuable, as it demonstrates documentary producers' uncompromising to power and capital. Such independent attitude is the important guarantee for the excellent quality and value of documentary. 


\section{ACTIVISM STYLE IN TAIWAN SOCIAL THEME DOCUMENTARY}

Zhang Tiezhi, a famous cultural critic in Taiwan, holds the opinion that "the purpose of social movement is not only to promote changes in social system, but also to change consciousness, value and philosophy. As a result, the traditional social mobilization and ways of protest are insufficient; the core objective of social movement must involve cultural transformation."[6] On the one hand, Taiwan documentary creators regard documentary as a tool to record society, shape the collective memory of the public and build the history of images of the public themselves, on the other hand, they take documentary as a carrier to realize the dialogue between creative subject and the public through documentary screening, documentary creation training, so as to promote the public to produce the ability of independent thinking and critique in the course of watching the film and learning. This is a way for cultural transformation by inspecting from the essence. "Activism is an action mode that takes image production as an important way to maintain social justice and promote social improvement. Although there are differences in terms of method, purpose and outcome, the common ground of image activism is not only to pay attention to the video works, but also attach importance to the process of shooting, screening and discussion of the video, so as to facilitate social transformation."[7] Activism has been an important mark of Taiwan social theme documentary, with the creator making and spreading the video with specific purpose.

The activism style in Taiwan social documentary was conceived prior to the abolishment of martial law in the middle of 1980s. At the end of 1986, Wang Zhizhang, Fu Dao and Li Sanchong formed a Green Team that recorded Taiwan's reform movement using portable camera. This team recorded large amount of non-party speeches, campaign and people's life using camera from the perspective of civil society, in order to break the information blockade and convey the truth of the scene. They recorded extensively the state of social transition and changes in Taiwan, and spread in a secret way, providing the images different from that of an official view to the public. The contents they shot involving the issues concerning politics, environmental protection, peasant movement, labor, indigenous peoples and veterans of other provinces. In conformity with the principle and attitude of not leaving history blank, they captured truth with their bodies and cameras. In addition, they broke through the information blockade of the mainstream media, leaving the precious history images of about three thousand hours. Their production was interfered by carious political forces due to sensitivity of the theme. However, they produced films and issued video tapes in a simple and fast way, and screened and sold them in social movement and selection occasion, striving to tell people the truth via spreading.

After the martial law was abolished, social movement in Taiwan was surging. The documentary creation teams such as Firefly Image that emerged later on took over the activism style of 1980s. In their view, camera was the tool and weapon for recording, and the symbol of showing the position of protest. "They eliminate the attempt to induce identity with non-emotional, calm and restrained images, and provide independent individual thinking space. As a result, the production of such documentaries is a kind of ideology in critical sense.[8]. Such documentaries kept a certain distance with official media and mainstream awareness. They produced images mainly through collection from civil society, thus avoided incorporation by mainstream ideology and the official, ensuring their own independence and publicity. They focused on shaping the thinking and perspective for the public to look at and think problems, and undertook the responsibility of holding together the publicity and fairness of social space. Problem elaborating and critical expression is not the ultimate purpose of these creators, as they aim to make documentaries to be the measurement and tool for promoting social reform progress and maintaining free and open public space

\section{CONCLUSION}

Excellent documentaries can mirror the style and characteristics of the times, reflect the pain and contradiction of the times, and attack the nature and background of society. Social theme documentary is the one most close to human living conditions and life scenes, and it records people's living conditions, emotional experience and inner demands under the historical background, concerns the relationship between human destiny and social development and changes. Sometimes, social documentary is like a sharp sword inserting the heart of bureaucracy; and sometimes it is like a probe, piercing at people's most indescribable pain. A group of social documentary creators in Taiwan can resist the utilitarian temptation and repression from the authority, and adhere to the free and independent spirit to express their opinions and views about objective fact. These social theme documentaries indicate great possibility in the course of development, and the problem awareness, critical spirit and activism style contained in them is a mirror, providing precious experience for documentary creators in other Chinese-speaking areas.

\section{REFERENCES}

[1] Sun Weichuan: Taiwan Movie in Post Martial Law Abolishment Era [M], The Commercial Press, 2014

[2] Guo Lixin: Making Inquiries against the Truth --- Political and Depolitical Documentary [M], Wheatfield Press, 2014

[3] Zhang Hongjun: On the Lack of Sense of Heaviness in Chinese Documentaries [J], Art Panorama, No.2, 2009

[4] Lv Xinyu: Writing and Shading --- Video, Media and Culture Collection [M], Guangxi Normal University Press, 2008

[5] Lin Mucai: Beyond the Scene --- Image of Taiwan Documentary Group [M] , Yuan-liou Publishing House, 2012

[6] Zhang Tiezhi: How to Attack with Culture, [EB/OL],http://news.artron.net/20070711/n30830.html

[7] Han Hong: Social Documentary and Image Activism --- Surveying Another Dimension of Chinese Social Documentary [J], Film Art, No.5, 2008.

[8] Luo Huiying: On the Creation and Aesthetics of Taiwan Documentary with Firefly Image Style [J], Journal of Beijing Film Academy, No. 4, 2012. 